\title{
BMJ Open Treatment outcomes for eating disorders in Sweden: data from the national quality registry
}

\author{
Per Södersten, Ulf Brodin, Jennie Sjöberg, Modjtaba Zandian, Cecilia Bergh
}

To cite: Södersten P, Brodin U, Sjöberg J, et al. Treatment outcomes for eating disorders in Sweden: data from the national quality registry. BMJ Open 2019;9:e024179. doi:10.1136/ bmjopen-2018-024179

\section{- Prepublication history and} additional material for this paper are available online. To view these files, please visit the journal online (http://dx.doi. org/10.1136/bmjopen-2018024179).

Received 14 May 2018 Revised 28 November 2018 Accepted 29 November 2018

Check for updates

(C) Author(s) (or their employer(s)) 2019. Re-use permitted under CC BY-NC. No commercial re-use. See rights and permissions. Published by BMJ.

Department of Neurobiology, Care Sciences and Society, Karolinska Institutet,

Mandometer Clinic, Huddinge, Sweden

Correspondence to Dr Per Södersten; per.sodersten@ki.se

\section{ABSTRACT}

Objective To report the outcomes of eating disorders treatment in Sweden in 2012-2016.

Design The number of patients treated and the number of patients not fulfilling an eating disorders diagnosis (remission) at 1 year of follow-up at the clinics listed in the National Quality Registry for Eating Disorders Treatment were analysed. The published outcomes at three clinics, which used survival analysis to estimate outcomes, were compared with their outcomes in the registry. Outcomes at the three biggest clinics were compared.

Setting All eating disorders clinics.

Participants All patients treated at eating disorders clinics.

Intervention Cognitive-behavioural therapy at most clinics and normalisation of eating behaviour at the three clinics with published outcomes.

Outcome measure Proportion of patients in remission. Results About 2600 patients were treated annually, fewer than half were followed up and remission rates decreased from $21 \%$ in 2014 to $14 \%$ in 2016 . Outcomes, which differed among clinics and within clinics over time, have been publicly overestimated by excluding patients lost to follow-up. The published estimated rate of remission at three clinics that treated 1200 patients in 1993-2011 was $27 \%, 28 \%$ and $40 \%$ at 1 year of follow-up. The average rate of remission over the three last years at the biggest of these clinics was $36 \%$ but decreased from $29 \%$ and $30 \%$ to 16 and $14 \%$ at the two other of the biggest clinics. Conclusions With more than half the patients lost to follow-up and no data on relapse in the National Quality Registry, it is difficult to estimate the effects of eating disorders treatment in Sweden. Analysis of time to clinically significant events, including an extended period of follow-up, has improved the quality of the estimates at three clinics. Overestimation of remission rates has misled healthcare policies. The effect of eating disorders treatment has also been overestimated internationally.

\section{INTRODUCTION}

The National Quality Registries in Sweden have been developed starting in the 1970s, and today, there are about 100 registries, covering virtually all kinds of disease. ${ }^{1}$ The Swedish Association of Local Authorities and Regions (SALAR) and the Swedish Government recently agreed to strengthen the registries financially, pointing to their key role in

\section{Strengths and limitations of this study}

This study has the strength of analysing all patients treated, followed up and treated to remission at all eating disorders clinics over 5 years in Sweden.

- These outcomes are available in the National Quality Registry for Eating Disorders Treatment but have not been published in the scientific literature.

- Three clinics have published outcomes at 3-month intervals making it possible to compare these outcomes with their outcomes in the registry.

- The study has the strength of showing that a timeto-event analysis improves compliance, facilitating estimation of outcomes.

- It is a limitation that whereas outcomes in the registry covered the years 2012-2016, the published outcomes at the three clinics covered the years 1993-2011.

the development of all aspects of healthcare, improving the quality of care, facilitating research, including international comparisons of outcomes, guiding healthcare policies and making it possible for anyone to compare the outcomes of treatment at individual clinics. ${ }^{12}$ Indeed, the SALAR has a website for such comparisons. ${ }^{3}$

The Swedish National Quality Registry for Eating Disorders Treatment, Riksät, was established in 1999 and has published 11 reports, written in Swedish, in 2001-2016. Following the aims of the registries, the objective of Riksät is to 'document the outcome of treatment' (quote from the first report in 2001). Thus, the important measures are the number of patients treated and the number of patients in remission at follow-up. These numbers are listed in Riksät but have not been analysed and reported in the scientific literature. The first aim of the present study is to examine the rate of remission at all eating disorders clinics in Sweden.

The results in Riksät have been publicised nationally as demonstrating increasing rates of remission over the years to $56 \%$ in 2015 and that " $70 \%$ of the patients are "cured" 
within 1 year'. ${ }^{45}$ Because these outcomes are better than the outcomes reported in the scientific literature, ${ }^{67}$ the second aim of this study is to examine their evidence basis.

There are three clinics in Sweden that have published outcomes. ${ }^{8}$ Because these clinics (Mandometer Clinics) also report to Riksät, it is possible to compare their published outcomes with their outcomes in Riksät. The biggest of the three Mandometer clinics is the clinic in the County Council of Stockholm (Mando). The third aim of this study is to compare the outcomes at Mando with the outcomes at the two other of the biggest clinics in Sweden, the Stockholm Centre for Eating Disorders (SCED) and the Capio Centre for Eating Disorders (Capio).

The fourth aim of this study is to call the attention of policy makers to the fact that outcomes of eating disorders treatment have been overestimated in Sweden and in other countries.

\section{METHODS}

\section{Patients and diagnostic procedures}

Riksät lists the number of patients entering treatment each year and the number of patients followed up 1 year later, although the exact time of follow-up is not mentioned. More than $90 \%$ of the patients entering treatment at the specialist clinics are listed in the registry, but patients that are treated at general psychiatric units may not be listed. While there is no information on how many these patients might be, most patients treated are listed in the registry. There is no information on long-term outcome, including relapse.

At the beginning of treatment and at follow-up, the patients completed the Eating Disorders Examination Questionnaire (EDE-Q), which measures eating disorders symptoms, ${ }^{9}$ and the Clinical Impairment Assessment (CIA), which measures psychosocial functioning as a consequence of the eating disorder. ${ }^{10}$ The EDE-Q was used for patients older than 10 years, and the CIA was used for patients older than 18 years. A semistructured interview was used for children and adults to determine overall psychiatric symptoms and social functioning (see, $\mathrm{eg}, \mathrm{ref}^{11}$ ). Using these procedures, the patients were diagnosed with anorexia nervosa, bulimia nervosa, eating disorder not otherwise specified or binge eating disorder relying on the criteria in the Diagnostic and Statistical Manual of Mental Disorders. ${ }^{12}$ Patients who no longer fulfilled the diagnostic criteria for an eating disorder were listed as in remission. About $4 \%-5 \%$ of the patients in the yearly reports had been treated before when entering treatment.

Riksät reports changes in the patients' social functioning and their experiences of the treatment, and these secondary measures improve in parallel as patients go into remission but will not be considered in this analysis.

While Riksät thus includes two time points for assessment, the Mandometer clinics have developed a treatment in which the patients are assessed at 3-month intervals and followed up 1, 2, 3, 6, 9, 12, 18, 24, 36, 48 and 60 months after remission. The procedures, including the criteria for inclusion, exclusion and remission, were published in $2002^{13}$ and have been republished many times (eg, ref 8); another description may be redundant. The Mandometer clinics also report their outcomes to Riksät.

\section{Treatments}

The 2012-2014 Riksät reports did not specify the treatments used beyond mentioning that these were guided by 'the principles of cognitive behavioural therapy' and that they could be used with individual patients or with groups of patients. Medical intervention was used for monitoring and restoring physical health, and psychopharmacology was also used; absence of evidence of their efficiency was pointed out. The 2015-2016 reports provide details on treatments. Thus, cognitive-behavioural therapy (CBT) was used with on average 52\% of the children and with $72 \%$ of the adults, psychodynamic therapy was used with on average $21 \%$ of the children and with $24 \%$ of the adults and family-based therapies were used with on average $38 \%$ of the children. The treatment developed at the Mandometer clinics was described in $1996,{ }^{14}$ republished some years on, ${ }^{813}$ and because it has since been described in several other papers, another description may be redundant. Suffice it to say that an important intervention is teaching patients how to eat normally using real-time visual feedback on how much food to eat and how quickly to eat it. A video of how this method works was published recently. ${ }^{15}$ In addition, the patients are provided with warmth, that exerts an anxiolytic effect in $30 \mathrm{~min},{ }^{16}$ their physical activity is reduced and they are assisted in restarting their social interactions. ${ }^{13}$ Interestingly, re-establishing normal eating behaviour is also the most important intervention in CBT, although it is not clear how this is achieved. ${ }^{7}$

\section{Description of outcomes}

Initially, Riksät reported the combined outcomes at the clinics across regions in Sweden, the reports published in 2009 and 2010 were incomplete, and no report was published in 2011. However, the outcomes at individual clinics were reported in 2012-2016. The number of patients treated at each clinic and the proportion of patients who were followed up are listed in one set of tables in these reports. The number and the proportion of patients in remission at follow-up are listed in another set of tables. These numbers have been combined into one table (online supplementary table) and used in the analysis.

\section{Combined outcomes at all clinics}

The numbers of patients treated, followed up and treated to remission have been summarised for all clinics. The number of patients in remission has been related to the number of patients treated as well as to the number of patients followed up in an attempt to explain the high remission rates publicised in Sweden. 
If the treatment and the follow-up assessments are about the same at all clinics, the probability for remission should be the same in all clinics. This hypothesis, which can be formalised as: $\mathrm{H}_{0}: \mathrm{P}_{\mathrm{i}}$ (Remission) $=\mathrm{P}_{0}$ (Remission) for all clinics, $\mathrm{i}=1,2,3, \ldots \mathrm{n}$, was tested using a test for homogeneity of the data. ${ }^{17}$

In 2012-2013, Riksät listed the number of clinics that treated and followed up at least 20 patients. The number of patients treated to remission at these clinics was listed in 2012, but in 2013, the number of patients treated to remission included clinics that had followed up at least 10 children or 10 adult patients. In 2014-2016, the number of patients treated, followed up and treated to remission was listed for all clinics. Using these data (online supplementary table), the number of clinics following up at least 20 patients have been analysed. Outcomes at clinics following up fewer than 10 patients have also been analysed.

\section{Published outcomes at Mandometer clinics}

Mandometer clinics have published the outcomes of 1428 patients treated at six clinics in four countries over various periods of time in 1993-2011, and these data are available in the online supplementary files of ref 8 . The three Swedish clinics, in Alingsås, Danderyd and Huddinge, treated 1200 of these patients. The clinic in Huddinge, within the Stockholm County Council, is the oldest clinic and is referred to as Mando in this analysis. The probability of going into remission over consecutive 3-month intervals up to 12 months at these clinics was estimated using a life-table approach to survival analysis. ${ }^{18}$ The rate of failure among censored patients was estimated to be $20 \%$, yielding a conservative estimate of treatment outcomes. This analysis allows comparison between these published outcomes and the outcomes for the same clinics listed in Riksät.

\section{Outcomes at individual clinics}

Outcomes were compared among SCED, Capio and Mando.

\section{Patient and public involvement}

This study is an analysis of patient data in a registry and those patients did not participate in the analysis. The results will be openly available at mandometer.com.

\section{RESULTS}

\section{Patient characteristics}

The characteristics of the patients at the start of treatment were stable over all years, and measures of variability are therefore not included. The average proportion of men was $4.6 \%$, and the average proportion of children and adolescents, who were $<18$ years old, was $29 \%$. The age, obviously, was variable, and the average mean (SD) age of all patients was 23.1 (8.9) years. The proportion of the various eating disorders diagnoses was also stable over the years, and average values are presented in table 1.
Table 1 Diagnoses among patients entering treatment for eating disorders in Sweden in 2012-2016

\begin{tabular}{lcc}
\hline & \multicolumn{2}{c}{ Proportion (\%) } \\
\cline { 2 - 3 } Diagnosis & Children & Adults \\
\hline Anorexia nervosa & 39 & 20 \\
Bulimia nervosa & 8 & 32 \\
Eating disorder not otherwise specified & 45 & 37 \\
Binge eating disorder & 1 & 6 \\
Other* & $\underline{7}$ & $\underline{5}$ \\
\hline
\end{tabular}

There were about 2600 patient each year and the proportions are averaged over these years. Children were $<18$ years old.

*Not specified.

\section{Combined outcomes at all clinics}

Figure 1 shows that the total number of patients treated at all clinics increased to about 2600 in 2013 and remained relatively stable over the following years. The figure also shows that fewer than half the patients were typically followed up a year later and that the rate of remission was about 21\% in 2012-2014 and decreased to 14\% in 2016. The number of patients treated to remission increased from 477 in 2012 to 589 in 2014 and decreased to 358 in 2016. There is no information on possible differences in the number of patients in remission related to the diagnosis at the start of treatment.

Figure 2 shows, first, that the rate of remission at all clinics that followed up their patients was less than $50 \%$ in 2012-2014, 29\% in 2015 and $36 \%$ in 2016. Second, the figure shows that the rate of remission at clinics that had treated at least one patient to remission increased to $56 \%$ in 2015 and decreased to $54 \%$ in 2016 . The second analysis thus excluded patients followed up at clinics that did not treat a single patient to remission. The significance of these two calculations of remission rates is clarified in the Discussion.

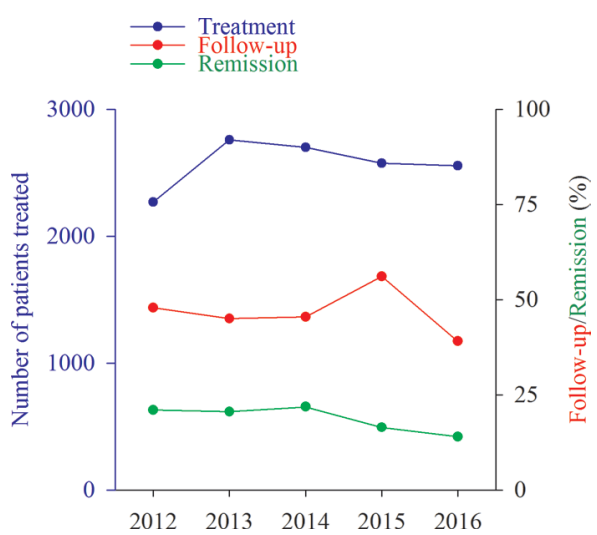

Figure 1 Number of patients treated at all clinics in Sweden and proportion of patients followed up and in remission 1 year later. The year on the $\mathrm{x}$-axis indicates the year of follow-up, the corresponding number of patients starting their treatment the year before. 


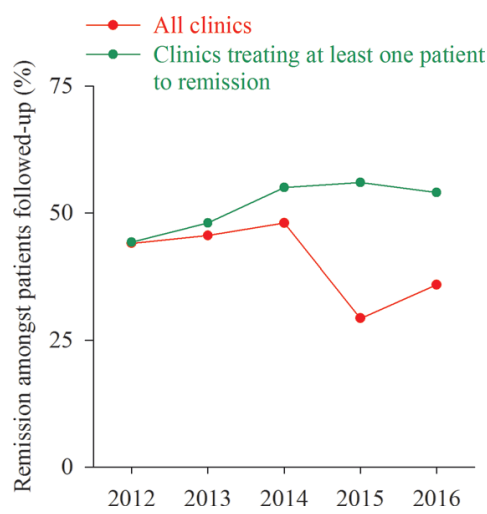

Figure 2 Proportion of patients in remission at all clinics that followed up their patients and at clinics that treated at least one patient to remission.

\section{Variability in outcomes}

The probability of going into remission in 2012 was significantly different among the 17 clinics that had treated patients in all recorded years $\left(\mathrm{p}<<0.001 ; \chi^{2}=80.2, \mathrm{df}=16\right)$. The probability of going into remission was also significantly different among the five clinics that had treated at least 100 patients in $2012\left(\mathrm{p}<0.001 ; \chi^{2}=23.7, \mathrm{df}=4\right)$. Analysis of the other years gives similar results.

Analysis of the results at SCED showed that the probability of going into remission was significantly different over the years $\left(\mathrm{p}<<0.001 ; \chi^{2}=46.3, \mathrm{df}=4\right)$. Analysis of the other clinics gives similar results.

\section{Combined outcomes at clinics that followed up at least 20 patients}

Because Riksät reported on clinics that had followed up at least 20 patients in 2012-2013 and for all clinics in 20142016, the number of clinics reporting their outcomes was lower in 2012-2013 (21 and 23) than in 2014-2016 (70, 64 and 59). However, it is possible to compare how many clinics had treated, followed up and treated at least 20 patients to remission in 2012-2016.

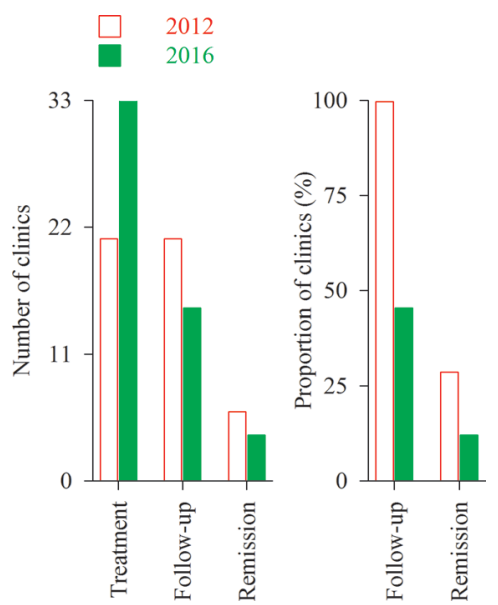

Figure 3 Number of clinics that treated, followed up and treated at least 20 patients to remission and proportion of clinics that followed up and treated at least 20 patients to remission in 2012 and 2016.

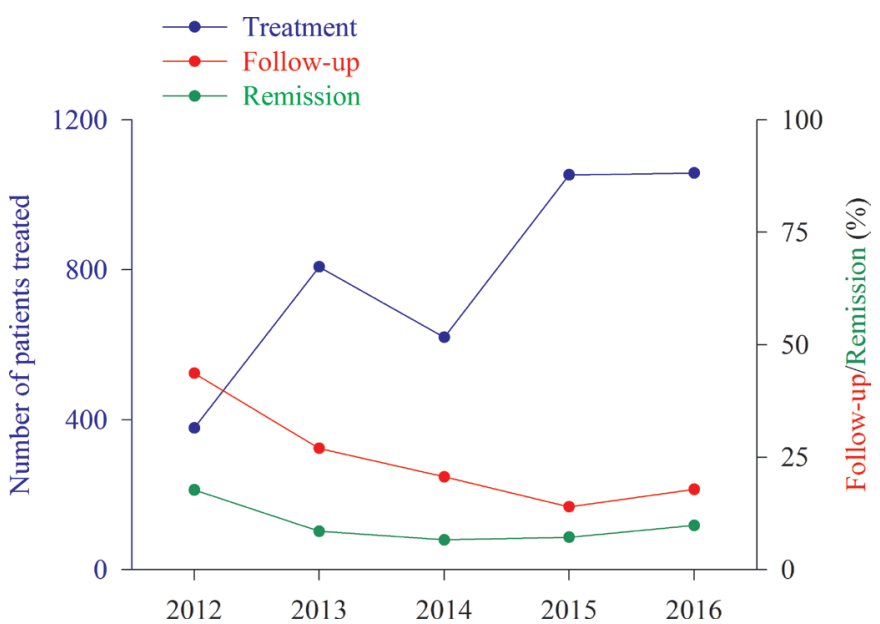

Figure 4 Number of patients treated at clinics that followed up fewer than 10 patients (2013-2016) or 20 patients (2012) and proportion of patients followed up and in remission one year later. The year on the $\mathrm{x}$ - axis indicates the year of follow-up, the corresponding number of patients starting their treatment the year before.

Figure 3 shows that more clinics had treated at least 20 patients in 2016 than in 2012. Whereas the clinics that had treated at least 20 patients in 2012 were selected for having followed them up, only $45 \%$ of these clinics followed up at least 20 patients in 2016. About one in three of these clinics had treated at least 20 patients to remission in 2012 compared with about one in eight in 2016. The results in the other years fall in between the results in 2012 and 2016.

Out of the 33 clinics that had treated at least 20 patients in 2016 (figure 2, green bar at the very left), three (9\%) had not followed up any patient and $21(64 \%)$ had not treated a single patient to remission. These 21 clinics had treated a total of 857 patients, with a median (range) of 32 (20-98) patients/clinic.

\section{Combined outcomes at clinics that followed up fewer than $\mathbf{1 0}$ patients}

Figure 4 shows that among the about 2600 patients who were treated annually in 2013-2016, the number of patients treated at clinics that followed up fewer than 10 patients increased to more than 1000 in the last 2 years. In parallel, the proportion of patients who were followed up and treated to remission at these clinics decreased. Fewer than 1 in 10 of the patients were treated to remission in the final 3 years. Please note that the values for 2012 include clinics that followed up fewer than 20 patients. Clinics following up fewer than 10 patients were not reported separately this year.

\section{Published outcomes at Mandometer clinics}

Table 2 shows that the proportion of patients in remission at 12 months assessments was at least $27 \%$ and significantly different at the three Mandometer clinics, whose outcomes are published. Treatment continues after the 12 months at these clinics and the proportion of patients in remission increases after various, prolonged periods of 
Table 2 Proportion of patients in remission at Mandometer clinics

\begin{tabular}{|c|c|c|c|}
\hline \multirow[b]{2}{*}{ Outcome } & \multicolumn{3}{|l|}{ Clinic } \\
\hline & Alingsås & Danderyd & Mando \\
\hline Operation (years) & 2 & 7 & 18 \\
\hline \multicolumn{4}{|l|}{ 12-month assessment } \\
\hline Patients in remission & 13 & 72 & 219 \\
\hline Patients not in remission & 36 & 107 & 552 \\
\hline Proportion in remission & 27 & $40^{*}$ & 28 \\
\hline $\begin{array}{l}\text { Continued treatment } \\
\text { (months) }\end{array}$ & 21 & 51 & 63 \\
\hline Patients in remission & 19 & 141 & 490 \\
\hline Patients not in remission & 27 & 27 & 170 \\
\hline Proportion in remission & 39 & $\underline{82}$ & $\underline{68}$ \\
\hline
\end{tabular}

${ }^{*} \mathrm{P}=0.0017$ compared with Alingsås and Mando after $\mathrm{p}=0.0069$ (overall difference).

time. Please note that these clinics had been operating over various periods of time.

It may be mentioned that the time to remission depends on the diagnosis at admission, with the longest time to remission for patients with anorexia nervosa. ${ }^{8}$

\section{Outcomes at the three biggest clinics}

SCED had treated about four times more patients annually (median: 715; range: 696-724) than Capio (175; 157-178) and Mando (123; 81-168), and followed up about the same proportion of patients $(43 ; 32 \%-69 \%)$ as Capio (50; 48\%-65\%) and Mando (43; 32\%-83\%). These proportions are similar to the average proportions of follow-up at all clinics over these years (figure 1).

Figure 5 shows that Mando had treated a bigger proportion of patients to remission than SCED and Capio in 2014-2016. While the rate of remission was relatively stable at on average $36 \%$ at Mando over these 3 years, it decreased from $29 \%$ to $16 \%$ at SCED and from $30 \%$ to $14 \%$ at Capio. In 2016, the proportion of patients treated

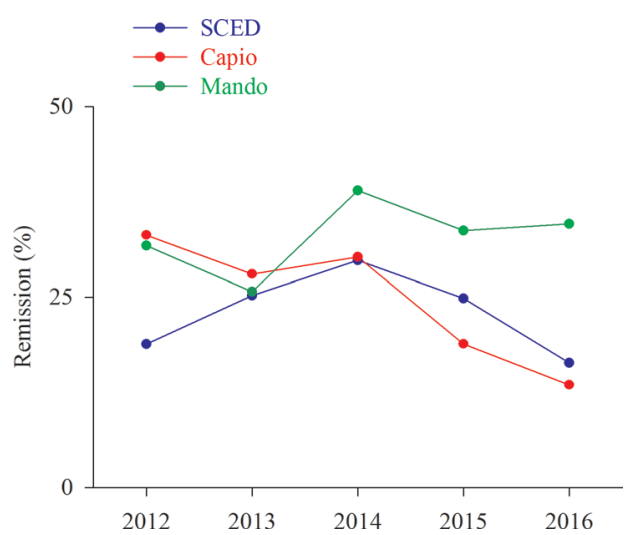

Figure 5 Proportion of patients treated to remission at the three clinics that treated more patients to remission than any other clinic, the Stockholm Centre for Eating Disorders (SCED), the Capio Centre for Eating Disorders (Capio) and the Mandometer Clinic in Stockholm (Mando). to remission at Mando (35\%) was about twice as big as the corresponding proportion at SCED (16\%) and Capio $(14 \%)$.

\section{DISCUSSION}

Patient characteristics, diagnostic procedures and treatments The characteristics of the patients, who have been treated for eating disorders in Sweden, including the proportion of males and children, age and diagnosis, have been relatively stable in recent years and are similar to the characteristics of eating disorders patients in other countries. ${ }^{19}$ It is worth noting that while a minority of the patients were diagnosed with binge eating disorder, that disorder is now the most common eating disorder. ${ }^{20}$ Although the diagnostic procedures may differ among clinics, ${ }^{19}$ most of the procedures used in Sweden have been developed in other countries. In addition, the treatments used in Sweden, including CBT, psychodynamic therapy and family therapy, as well as medical and psychopharmacological interventions aiming at restoring physical and mental health are the same as those recommended in the guidelines and used in most countries. ${ }^{19}{ }^{21-26}$ The treatment at the Mandometer clinics differs in that an important intervention is the normalisation of eating behaviour using real-time visual feedback on how to eat as described many times and most recently by video. ${ }^{15}$ The differences and similarities among the Mandometer treatment and CBT have been described in detail recently, including the differences in outcomes. ${ }^{7}$

\section{Outcomes in Sweden}

About 2600 patients were treated annually at the eating disorders clinics in Sweden in 2012-2016, fewer than half were followed up, and the proportion of patients treated to remission decreased from one in five in 2012 to less than one in seven in 2016. However, remission rates that are more than three times higher have been publicised nationally. These estimates were derived by excluding patients lost to follow-up and patients followed up at clinics that did not treat patients to remission. In 2016, only four clinics treated 20 patients to remission; most clinics treated a small number of patients, followed up a few and treated only one patient in 10 to remission. Outcomes varied significantly between clinics each year and within clinics over years. In addition, in 2016 more than half the 33 clinics that had treated on average 32 patients had failed to treat a single patient to remission; one of these clinics had treated 98 patients unsuccessfully.

\section{Interpretation and comparison with published outcomes}

While these findings indicate that the procedures of treatment and follow-up differ among clinics in Sweden, a word of caution seems appropriate. For example, although outcomes were significantly different over years at the biggest clinic (SCED), patients were treated to remission all years, suggesting that a statistically significant within-clinic variation may be less significant clinically. 
However, it seems unlikely that the decrease from a rate of remission of about $30 \%$ in 2014 at this clinic to about half that rate 2 years later is a matter of random variation, and the similar decrease in the rate of remission at another clinic in these years (Capio) suggests that the procedures at these clinics had deteriorated, at least temporarily.

Possible reasons for the variation in outcomes include changes in staffing, training of staff, patient compliance to treatment and the physical conditions in the clinics, factors that affect outcomes in multicentre clinical trials. ${ }^{27}$ While the 'study protocol' of the multicentre trial aims at reducing the influence of these factors, there is no standard protocol for the treatment of eating disorders, and although there is agreement that the treatment guidelines for eating disorders should be followed, this consensus view has not yet improved outcomes. ${ }^{21-2325}$ 28-30 For example, an attempt at implementing CBT, which is recommended in all guidelines, in combination with antidepressant medication for the treatment of bulimia nervosa in primary care in the USA resulted in a $70 \%$ dropout rate. ${ }^{31} \mathrm{~A}$ similar effort in general practice in the UK found that out of 683 patients with a diagnosis of bulimia, about half of the 272 patients who entered CBT completed the treatment, and although those patients improved, they were not free of eating disorders symptoms after treatment. ${ }^{32} \mathrm{~A}$ recent study aiming to implement CBT for anorexia nervosa in general practice produced similar results. Thus, out of 257 patient referrals, 44 patients started in treatment and 22 completed the treatment, ${ }^{33}$ findings that were replicated in another recent study. ${ }^{34}$ Compliance is thus a general problem in the treatment of eating disorders, not a 'Swedish' problem, but it can be improved as discussed below.

Whether these factors are causally related to the decrease in remission rates in 2015-2016 remains to be determined. However, it may be of some significance that as the number of patients treated at clinics that treated fewer than 10 patients to remission increased, the proportion of patients followed up and treated to remission decreased (Figure 3), and when the number of patients followed up at all clinics increased in 2015, there was a marked decrease in the proportion of patient treated to remission (figures 1 and 4).

The Mandometer treatment was developed starting in 1993, a theoretical framework and preliminary findings were reported in $1996 .{ }^{1435}$ A randomised controlled trial demonstrated its effectiveness, and outcomes for 1428 patients treated at six clinics in four countries were subsequently reported. ${ }^{813}$ The combined rate of remission at these clinics was estimated to be about $75 \%$ in on average 1 year of treatment, and the rate of relapse was estimated to be about $10 \%$ over 5 years of follow-up. ${ }^{8}$ Similar to Riksät, estimates were done among all patients entering treatment. However, far more patients were lost to follow-up at Riksät's 1 year time point of follow-up than to Mandometer's procedure of monitoring patients at 3-month intervals throughout treatment and at 1, 2, 3, 6, $9,12,18,24,36,48$ and 60 months of follow-up. ${ }^{8}$ Despite the difference, the rate of remission at the Mando clinic in the Stockholm County Council was on average $33 \%$ in 2012-2016 according to the Riksät calculation, which is about half the estimated published $75 \%$ rate of remission after on average 1 year of treatment. ${ }^{8}$ A comprehensive description of all patients, including those who take a long time to go into remission, is available in the online supplementary files of ref 8 , which reports outcomes at 3-month intervals at all Mando clinics.

Average remission rates should be viewed cautiously as outcomes varied between clinics. Thus, the published rate of remission at 12 months differed significantly at the three Mandometer clinics, yet it was higher than the average values reported for all clinics in each of the 5 years in Riksät. Differences in treatment methods between the Mandometer clinics and the other clinics may explain the differences in outcomes, ${ }^{7}$ and it is possible that outcomes will be more consistent at the Mandometer clinics once they have been operating for a longer period of time. For example, the Alingsås clinic had been treating patients for only 2 years and reached a rate of remission of only $39 \%$. The variation in the rate of remission at 12 months at the Mandometer clinics in Amsterdam (16\%), San Diego $(52 \%)$ and Melbourne $(25 \%)^{8}$ supports previous findings that international cultural and medical system differences also affect treatment outcomes. ${ }^{36}$ Thus, patients treated in San Diego improved rapidly, but they were often prevented from continuing in treatment because of the financial constraints of their insurance policies, ${ }^{8}$ a problem that would not affect patients in Sweden. It should be noted that relatively few patients had been treated at these clinics.

Dropout and relapse are significant events in the treatment of eating disorders, ${ }^{7}{ }^{738}$ and neither these events, nor remission, should be expected to occur after a predetermined period of time such as at 1 year of follow-up as used in Riksät. Also, the precise time for follow-up is not mentioned. It seems likely that this procedure explains why more than half the patients were lost to follow-up in Riksät. Practical approaches to survival analysis, including time-to-event analysis, are long available ${ }^{1839}$ and should be used in studies of outcomes of eating disorders treatment. The higher level of compliance at the Mandometer clinics $^{8}$ offers support for their value.

Considering the difference between outcomes at Mando and the other Swedish clinics, including the fact that several hundred patients have been treated to remission and that the rate of relapse has been reduced to an estimated $10 \%$ at the Mando clinics, a randomised controlled trial comparing outcomes at these clinics may be redundant; an attempt at a comparison ${ }^{40}$ was fraught with problems. ${ }^{8}$ The major treatment in Swedish clinics is $\mathrm{CBT}$, and a detailed analysis showed that the remission rates after CBT are lower than those after Mandometer treatment. ${ }^{7}$ Psychodynamic therapy is also used in Swedish clinics, although outcomes of this therapy are inferior to those of CBT. ${ }^{41}$ Similarly, the use of family-based therapies with children in Sweden as in other countries probably 
does not explain the differences in outcomes. Differences in patient characteristics at admission may contribute to differences in treatment outcomes and the possibility that such differences exist should be examined, although the published literature indicates that they do not. ${ }^{42}$ Also, there are no differences in the Swedish referral system such that more severely ill patients at one of the clinics might explain differences in outcomes.

\section{Implications for policy makers}

Overestimations of the outcomes of the treatment for eating disorders in Sweden have been publicised over several years, ${ }^{4}$ including the claim that ' $70 \%$ of the patients are "cured" within one year', which is maintained on Sweden's National Educational Radio Channel. ${ }^{5}$ This is similar to the international claim that CBT is "efficacious for a range of eating disorder presentations in the short and long-term, ${ }^{30}$ publicised as: 'Based on a solid empirical foundation, the transdiagnostic enhanced CBT approach will immediately become the gold standard for the treatment of eating disorders', ${ }^{43}$ and '[the effect of $\mathrm{CBT}]$ is the most dramatic that we have seen in the literature ... [including] the potency ... and the impressive maintenance of change over the 19 months follow-up'. ${ }^{44}$ The published evidence does not support these claims ${ }^{75-47}$ and evidence that the outcomes of CBT have been overestimated for the treatment of other disorders is gradually emerging. ${ }^{49}$ These overstatements have misinformed health policy makers and can now be corrected.

The importance of the National Quality Registries in guiding healthcare policies in Sweden was recently re-emphasised. ${ }^{50}$ In order to guide decisions on matters of healthcare, national and international registries must offer reliable information. Widely publicised 'facts' need to be critically examined. Policy makers should be aware that once ill-advised policies have been established, retrospectively controlling their evidence basis can be ineffective and even strengthen the misguided policy. ${ }^{51} 52$

Acknowledgements We would like to thank Sara Norring, Riksät; Anna Sandelin, the Centre of Registries Västra Götaland; and Fredrik Westander and Lale BjörneFergéus, SALAR, for information on Riksät.

Contributors PS examined the registry data in detail over the last 2 years. He reviewed his examinations for all authors at regular intervals during the examination period. He is responsible for the overall content as guarantor and assumes responsibility for all aspects of the work. All data used for the analysis are included as a supplementary table to this submission, which all authors are happy to share with other researchers. UB is medical statistician and has performed all statistical analyses and reviewed these for all authors at regular intervals during the examination period. JS is clinical director of the Mandometer Clinic in Alingsås and responsible for treatment and data collection and reporting to the registry in 2012-2016. MZ is clinical quality controller and has been responsible for data collection and reporting to the registry in 2012-2016. CB is clinical director for the Mandometer Clinic in Huddinge and responsible for treatment at all Mandometer clinics. All authors have seen and reviewed several versions of the manuscript and agreed to its final version. PS is the corresponding author and attests that all listed authors meet authorship criteria and that no others meeting the criteria have been omitted.

Funding This work was supported by The County Council of Stockholm grant number HNSV 15896, HSN 1502-0291, project 3252.
Disclaimer Role of the sponsor: the sponsor had no influence on the work.

Competing interests Complete openness concerning financial arrangements is intended here. UB, JS and MZ declare that they have no financial interests related to this study. Our research is carried out at the Karolinska Institute, where PS is a professor emeritus. The research is translated clinically by Mando Group AB, a company started by PS and CB, who have $47.5 \%$ of the stock each. Professor Michael Leon of the University of California at Irvine has $5 \%$. Mando Group AB contracts with the County Council of Stockholm every fifth year to treat patients with eating disorders. Mando Group AB signed its first contract in 1997 with the County Council of Stockholm and, since then, its treatment is one of the standards of care offered to the citizens of Stockholm. This arrangement is the same as when the County Council of Stockholm contracts with its own clinics to treat patients with all kinds of disease, including eating disorders. That is to say, the County Council of Stockholm provides eating-disorder services to the citizens of Stockholm both through a clinic of its own and through Mando Group AB. There is a third provider of care for patients with eating disorders in Stockholm, which is a private clinic. All healthcare in Sweden is funded through the tax system; private pay is extremely uncommon. It should be added, first, that Mando Group AB is in compliance with the recommendation of the International Committee of Medical Journal Editors on 'Author Responsibilities-Conflicts of Interest', http://www.icmje. org/recommendations/browse/roles-and-responsibilities/author-responsibilities-conflicts-of-interest.html. Second, it should also be added that all profit that Mando Group $A B$ has made has been reinvested in research and development and that there have been no dividends to stock owners. All of the above is declared in all manuscript submissions and thus far, journals have judged it necessary to publish only some of the details. It seems, however, that the potential ethical problem when scientists translate their research findings into the clinic in a company is not unlike that which arises when any scientist, in an academic setting, is developing a theory and needs further economic funding for his or her work and may receive recognition and financial benefits for the work. The incentive is, in part, economic in this case as well and the ethical 'problem' is similar in both cases. However, the more important incentive is the improvement of the treatment of patients with eating disorders. We are researchers working in an academic setting and like many other medical research institutes today, the Karolinska Institute encourages scientists to translate their research into the clinic in companies that aim to generate financial profits to be used for research and development (see: http://ki. se.proxy.kib.ki.se/sites/default/files/summary_strategy2018.pdf).

Patient consent Not required.

Ethics approval The project was approved by the Regional Ethical Review Board of Stockholm (Dnr 2015/456-31).

Provenance and peer review Not commissioned; externally peer reviewed.

Data sharing statement The data used for this analysis are available in a supplementary table.

Open access This is an open access article distributed in accordance with the Creative Commons Attribution Non Commercial (CC BY-NC 4.0) license, which permits others to distribute, remix, adapt, build upon this work non-commercially, and license their derivative works on different terms, provided the original work is properly cited, appropriate credit is given, any changes made indicated, and the use is non-commercial. See: http://creativecommons.org/licenses/by-nc/4.0/.

\section{REFERENCES}

1. Swedish Association of Local Authorities and Regions. Swedish national quality registries [Internet]. http://kvalitetsregister.se/ englishpages.2040.html (cited 7 May 2018).

2. Government Offices of Sweden. Överenskommelse om stöd till nationella kvalitetsregister under 2018 [Internet]. http://www. regeringen.se/overenskommelser-och-avtal/2017/12/nationellakvalitetsregister/ (cited 7 May 2018).

3. Swedish Association of Local Authorities and Regions. Vården $i$ Siffror [Internet]. https://vardenisiffror.se/ (cited 7 May 2018).

4. Birgegård $A$, Norring $C$, Norring $S$. National quality register for eating disorders treatment [Internet]. https://riksat.registercentrum.se/ (cited 7 May 2018).

5. von Hausswolff-Juhlin Y. Från evidens till praktiska råd [Internet]. https://urplay.se/program/203090-ur-samtiden-ny-kunskap-omatstorningar-fran-evidens-till-praktiska-rad (cited 7 May 2018).

6. Linardon J, Wade TD, de la Piedad Garcia X, et al. The efficacy of cognitive-behavioral therapy for eating disorders: A systematic review and meta-analysis. J Consult Clin Psychol 2017;85:1080-94. 
7. Södersten P, Bergh C, Leon M, et al. Cognitive behavior therapy for eating disorders versus normalization of eating behavior. Physiol Behav 2017;174:178-90.

8. Bergh C, Callmar M, Danemar S, et al. Effective treatment of eating disorders: Results at multiple sites. Behav Neurosci 2013;127:878-89.

9. Fairburn C, Cooper Z, O'Connor M. Eating disorders examination (16.0D): In. Fairburn C, ed. Cognitive behavior therapy and eating disorders. New York, N.Y: Guilford Press, 2008.

10. Bohn K, Fairburn CG. Clinical impairment assessment questionnaire (CIA 3.0): In. Cognitive behavior therapy for eating disorders. N.Y: New York: Guildford Press:315-7.

11. Aas $\mathrm{IH}$, Ihm A. Global Assessment of Functioning (GAF): properties and frontier of current knowledge. Ann Gen Psychiatry 2010;9:20.

12. American Psychiatric Association. fourth edDiagnostic and Statistical Manual of Mental Disorders. . Washington, D.C: American Psychiatric Association, 1994.

13. Bergh C, Brodin U, Lindberg G, et al. Randomized controlled trial of a treatment for anorexia and bulimia nervosa. Proc Natl Acad Sci U S A 2002;99:9486-91.

14. Bergh $\mathrm{C}$, Eklund S, Eriksson M, et al. A new treatment of anorexia nervosa. The Lancet 1996;348:611-2.

15. Esfandiari M, Papapanagiotou V, Diou C, et al. Control of Eating Behavior Using a Novel Feedback System. J Vis Exp 2018;08.

16. Zandian M, Holmstedt E, Larsson A, et al. Anxiolytic effect of warmth in anorexia nervosa. Acta Psychiatr Scand 2017;135:266-7.

17. Kirkwood BR, Sterne JAC. Essential Medical Statistics. Blackwell, Oxford, 2003.

18. Tableman M, Kim JS. Survival Analysis Using S: Analysis of Time-toEvent Data. Boca Raton, FL: Chapman \& Hall/CRC, 2004.

19. Treasure J, Claudino AM, Zucker N. Eating disorders. The Lancet 2010;375:583-93.

20. Erskine HE, Whiteford HA. Epidemiology of binge eating disorder. Curr Opin Psychiatry 2018;31:462-70.

21. af Sandeberg A-M, Birgegård A, Mohlin L, et al. Regionalt vårdprogram - ätstörningar [Internet]. http://www1.psykiatristod.se/ Global/vardprogram_fulltext/RV_Atstorningar_2009_updat2010.pdf (cited 7 May 2018).

22. Hay P, Chinn D, Forbes D, et al. Royal Australian and New Zealand College of Psychiatrists clinical practice guidelines for the treatment of eating disorders. Aust N Z J Psychiatry 2014;48:977-1008.

23. Hay PP, Bacaltchuk J, Stefano S, et al. Psychological treatments for bulimia nervosa and binging. Cochrane Database Syst Rev 2009;4:CD000562.

24. Hay P. A systematic review of evidence for psychological treatments in eating disorders: 2005-2012. Int J Eat Disord 2013;46:462-9.

25. Zipfel S, Giel KE, Bulik CM, et al. Anorexia nervosa: aetiology, assessment, and treatment. Lancet Psychiatry. 2015;2:1099-111.

26. Treasure J, Zipfel S, Micali N, et al. Anorexia nervosa. Nat Rev Dis Primers 2015;7:15074.

27. Guthrie LB, Oken E, Sterne JA, et al. Ongoing monitoring of data clustering in multicenter studies. BMC Med Res Methodol 2012;12:29.

28. Allen S, Dalton WT. Treatment of eating disorders in primary care: a systematic review. J Health Psychol 2011;16:1165-76.

29. Le Grange D, Hughes EK, Court A, et al. Randomized clinical trial of parent-focused treatment and family-based treatment for adolescent anorexia nervosa. J Am Acad Child Adolesc Psychiatry 2016;55:683-92.

30. Linardon J, Fairburn CG, Fitzsimmons-Craft EE, et al. The empirical status of the third-wave behaviour therapies for the treatment of eating disorders: A systematic review. Clin Psychol Rev 2017;58:125-40.
31. Walsh BT, Fairburn CG, Mickley D, et al. Treatment of bulimia nervosa in a primary care setting. Am J Psychiatry 2004;161:556-61.

32. Knott S, Woodward D, Hoefkens A, et al. Cognitive behaviour therapy for bulimia nervosa and eating disorders not otherwise specified: Translation from randomized controlled trial to a clinical setting. Behav Cogn Psychother 2015;43:641-54.

33. Frostad S, Danielsen YS, Rekkedal GÅ, et al. Implementation of enhanced cognitive behaviour therapy (CBT-E) for adults with anorexia nervosa in an outpatient eating-disorder unit at a public hospital. J Eat Disord 2018;6:12.

34. Jenkins PE, Morgan C, Houlihan C. Outpatient CBT for underweight patients with eating disorders: effectiveness within a National Health Service (NHS) eating disorders service. Behav Cogn Psychother 2018:1-13.

35. Bergh C, Södersten P. Anorexia nervosa, self-starvation and the reward of stress. Nat Med 1996;2:21-2.

36. Wright JG, Katz JN, Losina E. Clinical trials in orthopaedics research. Part I. Cultural and practical barriers to randomized trials in orthopaedics. J Bone Joint Surg Am 2011;93:e15.

37. Linardon J, Hindle A, Brennan L. Dropout from cognitive-behavioral therapy for eating disorders: A meta-analysis of randomized, controlled trials. Int J Eat Disord 2018;51:381-91.

38. Berends T, Boonstra N, van Elburg A. Relapse in anorexia nervosa: a systematic review and meta-analysis. Curr Opin Psychiatry 2018;31:445-455.

39. Pocock SJ. Clinical Trials: A Practical Approach. First. Chichester West Sussex. New York: Wiley, 1984:278.

40. van Elburg AA, Hillebrand JJ, Huyser C, et al. Mandometer treatment not superior to treatment as usual for anorexia nervosa. Int $\mathrm{J}$ Eat Disord 2012;45:193-201.

41. Poulsen S, Lunn S, Daniel SI, et al. A randomized controlled trial of psychoanalytic psychotherapy or cognitive-behavioral therapy for bulimia nervosa. Am J Psychiatry 2014;171:109-16.

42. Södersten P, Bergh C, Leon M, et al. Dopamine and anorexia nervosa. Neurosci Biobehav Rev 2016;60:26-30.

43. Fairburn CG. Cognitive Behavior Therapy and Eating Disorders. New York: The Guilford Press, 2008.

44. Hollon SD, Wilson GT. Psychoanalysis or cognitive-behaviora therapy for bulimia nervosa: the specificity of psychological treatments. Am J Psychiatry 2014;171:13-16.

45. Lampard AM, Sharbanee JM. The Cognitive-Behavioural Theory and Treatment of Bulimia Nervosa: An Examination of Treatment Mechanisms and Future Directions. Aust Psychol 2015;50:6-13.

46. Troscianko ET. CBT for eating disorders: A not-yet-success story [Internet]. https://www.psychologytoday.com/us/experts/emilytroscianko (cited 8 May 2018)

47. Gutiérrez E, Carrera O. Anorexia nervosa treatments and Occam's razor. Psychol Med 2018;48:1390-1.

48. Christensen H, Mackinnon AJ. Review: computerised CBT improves adult depression in the short-term, but its effect may have been overestimated previously. Evid Based Ment Health 2013;16:119.

49. Steinert C, Munder T, Rabung S, et al. Psychodynamic therapy: As efficacious as other empirically supported treatments? A meta-analysis testing equivalence of outcomes. Am J Psychiatry 2017;174:943-53.

50. Granström E, Hansson J, Sparring V, et al. Enhancing policy implementation to improve healthcare practices: The role and strategies of hybrid national-local support structures. Int J Health Plann Manage 2018.

51. Lewandowsky S, Ecker UK, Seifert CM, et al. Misinformation and its correction: Continued influence and successful debiasing. Psychol Sci Public Interest 2012;13:106-31.

52. Fazio LK, Brashier NM, Payne BK, et al. Knowledge does not protect against illusory truth. J Exp Psychol Gen 2015;144:993-1002. 